\title{
ARTIFICIAL FEVER THERAPY OF SYPHILIS AND GONOCOCCIC INFECTIONS
}

By WALTER M. SIMPSON, M.S., M.D., F.A.C.P*., Director, Kettering Institute for Medical Research, Miami Valley Hospital, Dayton, Ohio.

THE monumental researches of the Viennese physician, Julius Wagner-Jauregg, ${ }^{1}$ announced in I9I8, provided the stimulus which has led to the present remarkable interest in artificial fever therapy. For centuries, most physicians regarded fever as an alarming symptom of disease. After Virchow had ascribed various degenerative tissue changes to the effect of fever, the use of antipyretic drugs became common practice. Since WagnerJauregg's demonstration that artificial fever, induced by malaria inoculata, was frequently capable of overcoming the ordinarily disastrous effects of syphilis of the central nervous system, it has become more and more apparent that fever is one of the most important mechanisms of defence against infection. There is a growing body of evidence which indicates that fever exerts an adverse influence upon the growth of certain bacteria, diminishes the potency of toxins, favours phagocytosis and stimulates the development of immune bodies. ${ }^{2}$

Wagner-Jauregg's success in the malaria therapy of dementia paralytica was soon confirmed by investigators in many parts of the world. The inherent dangers of engrafting one serious disease upon another as a therapeutic measure naturally led to a diligent search for a less hazardous method for producing a similar effect. Comparable results were obtained by other workers following inoculations with the organisms of rat-bite fever and relapsing fever. Repeated injections of vaccines prepared from typhoid or paratyphoid organisms or from Hamophilus ducreyi, heteroproteins such as milk or peptone,

* With the collaboration of Charles F. Kettering, Sc.D. ; Edwin C. Sittler, B.S. in Engineering; Fred. K. Kislig, M.D. (deceased) ; H. Worley Kendell, M.D. ; L. G. Kauffman, M.D. ; Arthur M. Culler, M.D. ; and Jerome Hartman, M.D.

Based on an address delivered before the Medical Society for the Study of Venereal Diseases on May 22nd, 1936. 
and chemical substances such as sulphur, have yielded comparable results in those cases in which sustained high fever was induced. It became more and more apparent that simple fever production was the important, if not the only, factor in the production of similar therapeutic results with such a wide variety of fever-producing agencies. It was natural that these observations should stimulate a search for physical methods for artificial fever production.

Schamberg and Rule (I926), and Mehrtens and Pouppirt (I929) reintroduced the prolonged hot bath for thermotherapy. Rosanoff (I928) reintroduced the outmoded hot air method. Neymann and Osborne (I929), King and Cocke (I930), and Whitney (I930) introduced the use of high frequency electric currents (diathermy and radiothermy).

Investigations in the artificial production of fever by physical methods were begun at the Miami Valley Hospital in I93I. Several months of experimentation with hot baths, hot air, electric blankets and diathermy convinced us that these physical modalities possessed inherent hazards, even though comparable clinical results could be obtained with any of these methods.

Experiments were then begun with an ultra-high frequency oscillator, known as the radiotherm, developed by Whitney and his associates ${ }^{3}$ in the Research Laboratories of the General Electric Company. The apparatus was essentially a I-kilowatt radio transmitter in which the condenser discharges were concentrated between two large metal plates instead of being directed from an aerial. The apparatus produced a high-frequency field of approximately Io million cycles per second (30 metre waves) between the condenser plates. Early in the course of this investigation it became apparent that the comfort of the patient would be greatly enhanced by utilising some form of insulated air-conditioned cabinet. This measure was necessitated by the fact that the short radio waves became concentrated in the drops of sweat which accumulated on the skin surface, producing arcing and burning. With the collaboration of $\mathrm{Mr}$. Charles $\mathrm{F}$. Kettering and Mr. Edwin C. Sittler, of the Research Laboratories of the General Motors Corporation, a simple and efficient air-conditioned cabinet was devised. ${ }^{4} \mathrm{We}$ were convinced, however, that the high cost and com- 


\section{ARTIFICIAL FEVER THERAPY}

plexity of the combined radiotherm and air-conditioned cabinet militated against its usefulness.

After two years of constant experimentation with various modifications of the apparatus, an accidental observation caused us greatly to alter the method of producing and maintaining artificial fever. While subjecting a child with congenital syphilis to artificial fever therapy by the combined radiotherm and air-conditioned cabinet method, the nurse-technician failed to turn on the switches controlling the output of the high-frequency currents. The rectal temperature reached the desired level of Io6 F. (4I.I C.) in the usual time (fifty minutes). It was then discovered that the high-frequency currents had not been utilised for fever induction. By adjusting the air temperature-humidity factors in the air-conditioned cabinet the temperature was maintained at this level for the usual five-hour period.

This fortunate occurrence led us to develop a much simpler, safer, less costly and more easily controllable air-conditioned apparatus (Kettering hypertherm) for fever production and maintenance (Fig. I). Highfrequency currents are no longer employed. Deep tissue temperature studies made with thermocouples revealed no essential difference in deep heating effect when fever was produced by either high-frequency currents (diathermy or radiothermy) or by conditioned air alone.

In its present state the Kettering hypertherm* consists of an insulated cabinet in which the nude patient lies, with his head extending outside the cabinet. Spongerubber insulation is utilised in the neck region to permit the patient to shift his position. The patient lies on an air mattress, supported by a boxlike bed, which is rolled in and out at will. In the rear of the cabinet is a small insulated fireproof compartment in which the air-conditioning apparatus is housed. The dry-bulb air temperature is controlled by a thermostat. The percentage of relative humidity is controlled by a humidistat. The air velocity within the cabinet is controlled by blowers of

* Fifty-five of these units have been lent to twenty medical research centres, strictly for investigative purposes. The physicians and nurses charged with this undertaking received special training in the Department of Fever Therapy Research at the Miami Valley Hospital before the apparatus was released. A simpler, smaller and less costly apparatus is now being developed. It is probable that this apparatus will ultimately be available on a loan-lease basis to certain qualified institutions. 


\section{BRITISH JOURNAL OF VENEREAL DISEASES}

fixed speed. The average set of air conditions to which the patient's body is subjectea during fever induction is as follows : dry-bulb air temperature of from $130^{\circ}$ to I $50^{\circ} \mathrm{F}$. $\left(54^{\circ}-65^{\circ} \mathrm{C}\right.$. $)$, relative humidity of from 35 to $5^{\circ}$ per cent., and air velocity of 425 cubic feet per minute.

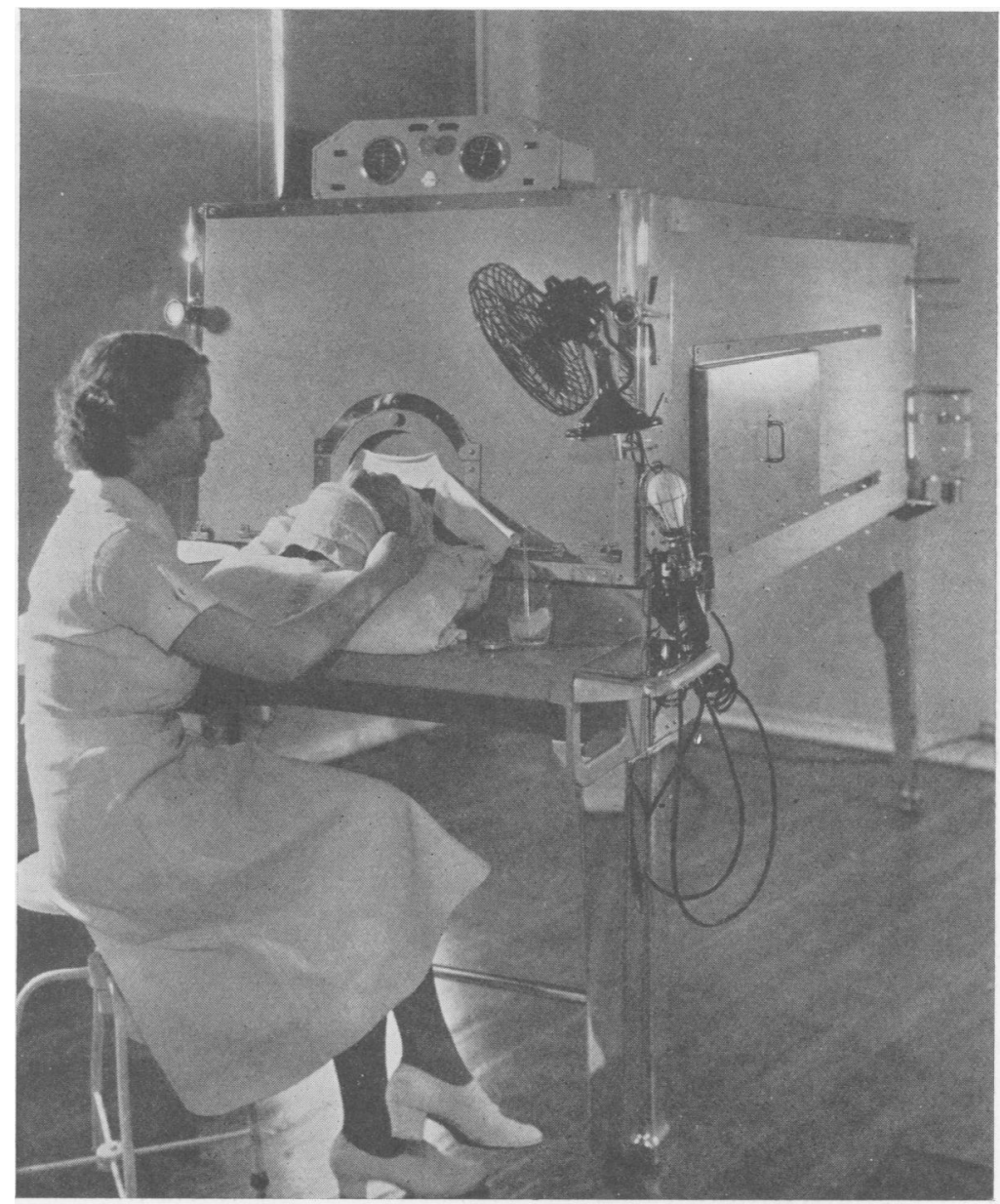

FIG. I.-The Kettering Hypertherm.

The elevation of the rectal temperature to $105^{\circ} \mathrm{F}$. $\left(40 \cdot 6^{\circ} \mathrm{C}\right.$.) is ordinarily accomplished in from forty minutes to one hour. During fever maintenance the dry-bulb temperature and air velocity are reduced. The air is constantly conditioned by continuous passage through the air-conditioning compartment. The safety and com-

$$
\text { I36 }
$$


fort of the patient are greatly enhanced by the accurate control of the relative humidity.

The mechanism of fever induction with the Kettering hypertherm depends primarily on heat transfer by conduction from the circulating heated air. This factor, combined with prevention of the normal rate of heat loss from the body by radiation and evaporation, is responsible for the elevation of the body temperature and its maintenance at any desired level.

The simplification of the apparatus and the removal of hazards inherent in certain other physical modalities, have converted this form of therapy from one requiring hospitalisation to one in which the patient is usually able to return to his work on the day following treatment.

Early in the course of this investigation we ${ }^{5}$ discovered that the sense of exhaustion commonly experienced by many of our patients could be largely overcome by supplying large quantities of chloride-containing fluids. Most patients lost between 2 and 5 litres of sweat during a five-hour treatment at $106^{\circ} \mathrm{F} .\left(4 \mathrm{I} \cdot \mathrm{I}^{\circ} \mathrm{C}\right.$. $)$. The blood chloride values exhibited an average decline of $40 \mathrm{mg}$. per cent. at the end of the febrile period in approximately 80 per cent. of the patients. In five instances the fall exceeded Ioo mg. per cent. Some patients exhibited such evidences of hypochloremia as nausea, vomiting, abdominal cramps, muscular twitchings or tetany. Chemical analysis of the sweat revealed an average sodium chloride content of $650 \mathrm{mg}$. per cent. Thus, from 20 to 26 grams of sodium chloride were being withdrawn from the blood and tissues during each treatment. Repeated gastric analyses revealed that the free hydrochloric acid completely disappeared during the first thirty to ninety minutes. These findings suggested the advisability of supplying chlorides during and immediately after each treatment. It was immediately apparent that the ingestion of 2-4 litres of 0.6 per cent. sodium chloride solution (iced) largely abolished the symptoms of hypochloremia. If nausea and vomiting persist, or if the patient is unable to take the required amount of chlorides by mouth, from 500 to $\mathrm{I}, 000$ c.c. of a solution containing Io per cent. of dextrose and I per cent. of sodium chloride is slowly injected intravenously, without interruption of the treatment. 


\section{TREATMENT}

During the past five years we have subjected 43I patients to 3,204 artificial fever treatments (approximately I7,000 hours of sustained fever). With the exception of occasional mild skin burns which occurred particularly at the beginning of this undertaking, no person has been injured by the treatments. One hundred and ninety-three patients, who have been under observation for six months to four and a half years, have been treated for syphilis or gonococcic infection. Those patients who did not co-operate during the course of treatments or during the post-treatment progress studies, and all patients who have been under observation for less than six months, are excluded from consideration. There were 3I patients who received treatment for primary and early secondary syphilis ; 89 for neurosyphilis, ocular syphilis or resistant seropositive syphilis. Forty-five patients were treated for gonococcic arthritis ; 28 patients received treatment for gonococcic infection other than gonococcic arthritis.

\section{Treatment of Syphilis}

Many observers ${ }^{6}$ have found fever therapy combined with or followed by chemotherapy to be more effective than fever therapy alone in the treatment of neurosyphilis. On this basis we have combined chemotherapy, usually in the form of bismuth arsphenamine sulphonate (Bismarsen), with the fever treatments. In some patients neoarsphenamine (thirty injections, each containing $0 \cdot 3$ gm.) and bismuth (thirty injections, each containing $0.2 \mathrm{gm}$. of metallic bismuth) therapy was substituted. One advantage of the induction of artificial fever by physical methods is that the antisyphilitic drug may be given during the course of fever treatments. It is our practice to inject the antisyphilitic drug half an hour before the fever treatment is begun, on the basis that the general vasodilatation which occurs during sustained high fever may permit greater diffusion of the chemical substances. Bratz ${ }^{7}$ believes that fever produced by malaria increases the permeability of the small vessels of the brain and permits protective substances to reach the diseased brain tissues. After the ten sessions of fever I38 


\section{ARTIFICIAL FEVER THERAPY}

therapy plus chemotherapy, twenty injections of the antisyphilitic chemical agents are given, at weekly intervals.

We have regarded a minimum course of artificial fever therapy for patients with syphilis to consist of fifty hours of sustained fever between $105^{\circ}$ and $106^{\circ} \mathrm{F}$. $\left(40 \cdot 6^{\circ}-4 \mathrm{I} \cdot \mathrm{I}^{\circ} \mathrm{C}\right.$.). This more or less arbitrary choice is based on the observation that the highest remission rate following malaria therapy occurred in patients who had experienced at least fifty hours of fever above $102^{\circ} \mathrm{F}$. $\left(39^{\circ} \mathrm{C}\right.$.). The treatments are usually given in ten weekly sessions, each of five or more hours' duration. Many patients experience the most marked improvement after five or six treatments; a few require more than ten.

All patients are subjected to a thorough diagnostic survey to determine eligibility for fever therapy. Special studies are made of cardiac, vascular and renal functions, including electrocardiographic studies, basal blood-pressure determinations and blood chemical analyses. Blood and spinal fluid serologic reactions, spinal fluid cell count, protein and sugar content, and colloidal gold reactions are determined before treatment is begun, at the end of the combined fever-chemotherapy regimen, and at intervals of six months thereafter. As an additional control measure duplicate blood and spinal fluid specimens from these patients were submitted to Kahn in the laboratories of the University of Michigan Hospital for repetition of the serologic examinations. The Kahn standard diagnostic, presumptive and quantitative procedures* were carried out in those laboratories, without any knowledge of the clinical condition of the patients, and reported to us. ${ }^{8}$ Old age (above sixty years), cardiac or renal insufficiency, advanced cardiovascular syphilis, aortic aneurysm, and the demented form of advanced dementia paralytica are regarded as contraindications. Patients between forty-five and sixty years of age are treated with great caution. One or more mild treatments are usually given such individuals as a test of cardiac function. Occasionally treatments are spaced two weeks apart.

\section{EARLy SyPhILIS}

For centuries laymen have known that sustained heat exerts a favourable influence on the cutaneous lesions of

* The Kahn quantitative procedure was found to provide a reliable and sensitive index of therapeutic response. 


\section{BRITISH JOURNAL OF VENEREAL DISEASES}

syphilis. The popularity of balneotherapy in many parts of the world has persisted since the ancient Greek priestphysicians first converted their thermal springs into baths. While emphasis has been placed on the mineral content of the waters, it now appears that the virtue of balneotherapy lies in its ability to produce local or general fever. The advent of scientific methods for the controlled production of fever provides a rational explanation for some of the results attained with the purely empirical use of these older methods.

There is a rapidly accumulating mass of experimental data which provides strong evidence of the unfavourable influence of high body temperature on Spirochata pallida. Many observers have reported their inability to find spirochetes in the brain tissue of patients who have died following malaria therapy.

In I9I9 Weichbrodt and Jahnel ${ }^{9}$ placed rabbits with scrotal chancres in a thermostatically controlled incubator with the air temperature at $105.8^{\circ} \mathrm{F} .\left(4 \mathrm{I}^{\circ} \mathrm{C}\right.$. $)$. The temperature elevation in the rabbits induced by this procedure ranged from $104^{\circ}$ to $107 \cdot 6^{\circ} \mathrm{F}$. $\left(40^{\circ}-42^{\circ} \mathrm{C}\right.$. $)$. The rabbits were subjected to this treatment for thirty minutes once or twice daily for from three to five weeks. After the second day the spirochetes gradually lost their motility, declined in number and disappeared. The chancres healed much more rapidly than in untreated rabbits.

Schamberg and Rule 10 in 1926 demonstrated that eleven hot baths on consecutive days, producing an average rise in the rabbits' temperature of $4^{\circ} \mathrm{F} .\left(2 \cdot 2^{\circ} \mathrm{C}\right.$.), when begun four days after the intratesticular inoculation of Spirochata pallida, would prevent the development of syphilitic lesions. They found that spirochetes heated on a water bath to $I^{\circ} 6^{\circ} \mathrm{F}$. $\left(4 \mathrm{I} \cdot \mathrm{I}^{\circ} \mathrm{C}\right.$.) for six hours lost their motility and began to disintegrate. Their next experiment ${ }^{11}$ showed that well-developed chancres of the scrotum of the rabbit disappeared after fifteen daily hot baths, each of fifteen minutes' duration. The average elevation of the rabbits' temperature was from $5.2^{\circ}$ to $5 \cdot 8^{\circ} \mathrm{F} .\left(2 \cdot 9^{\circ}-3 \cdot 2^{\circ} \mathrm{C}\right.$. $)$. In eight days the spirochetes had disappeared. The testicles were entirely normal in seventeen days. To determine whether the infection was completely extinguished, the popliteal and inguinal lymph glands were removed on the seventy-sixth day and injected into the testes of another rabbit. Eighty- 


\section{ARTIFICIAL FEVER THERAPY}

seven days after the inoculation there was no evidence of infection. These experiments demonstrated that syphilis in the rabbit can be prevented and that primary syphilis in the rabbit can be cured by hot baths. In this connection, Schamberg states: "The interesting query arises whether extremely hot baths might be effective as a prophylactic measure after exposure."

Schamberg and Rule ${ }^{\mathbf{1 2}}$ then employed hot baths on eleven human beings with syphilis. The patients received from one to fourteen baths, with an elevation of mouth temperature to $105^{\circ}-106^{\circ} \mathrm{F}$. $\left(40 \cdot 6^{\circ}-4 \mathrm{I} \cdot \mathrm{I}^{\circ} \mathrm{C}\right.$.) for from thirty to fifty minutes. The eruptive lesions underwent marked and rapid regression. The serologic reactions were favourably influenced in practically all instances. At the conclusion of these observations all were given the usual antisyphilitic chemotherapy. Schamberg and Tseng ${ }^{13}$ applied similar experiments to a few human syphilitic subjects, with essentially similar results.

Bessemans ${ }^{14}$, of Ghent, and his associates have made valuable studies which demonstrate the feeble thermoresistance of Spirocheta pallida. With the ingenious use of small thermocouples inserted into the scrotal chancres of rabbits it was shown that primary syphilis was cured by either local or general balneothermotherapy or aerothermotherapy when the tissue temperature of the chancre was sustained at $104^{\circ} \mathrm{F}$. $\left(40^{\circ} \mathrm{C}\right.$.) for two hours or at I07. $6^{\circ} \mathrm{F}$. $\left(42^{\circ} \mathrm{C}\right.$.) for one hour. Raising the rabbits' intratesticular temperature to the same levels after inoculation prevented the development of the disease.

The important $\mathrm{r}$ searches of Carpenter, Boak and Warren ${ }^{15}$ again emphasise the thermolability of Spirochata pallida and "suggest the practicality of fever therapy in the treatment of acute as well as chronic syphilis in man." Utilising heat produced by the short radio waves of an ultra-high frequency oscillator, they were able to prevent the development of chancres in twenty-one of twenty-five rabbits when treatments were begun four, five and seven days after inoculation. In one treated rabbit a chancre developed, while the testis of another became edematous and indurated ; increasing the duration and number of heatings caused the rabbits to become normal; ' two rabbits died. Eighteen untreated control rabbits developed the typical lesions of experimental syphilis. These workers also found that 


\section{BRITISH JOURNAL OF VENEREAL DISEASES}

multiple unsustained fevers of from I05. $8^{\circ}$ to $107.6^{\circ} \mathrm{F}$. $\left(4 \mathrm{I}^{\circ}-42^{\circ} \mathrm{C}\right.$.) destroyed Spirochata pallida in rabbits with active syphilitic lesions, as determined by reinoculation experiments. It was also found that one febrile period of six hours at a temperature of $106 \cdot 7^{\circ}-107 \cdot 6^{\circ} \mathrm{F}$. $\left(4 \mathrm{I} \cdot 5^{\circ}-\right.$ $42^{\circ}$ C.) was sufficient to destroy Spirochata pallida. The time interval between inoculations and fever treatment, or between the end of fever treatment and reinoculation, did not affect the results. Hence the fever treatment was effective at any stage of experimental syphilis in rabbits. The same authors investigated the thermal death-time gradient of Spirochata pallida in testicular extracts in vitro. Five hours of temperature at $102 \cdot 2^{\circ} \mathrm{F}$. $\left(39^{\circ} \mathrm{C}\right.$. $)$, three hours at $104^{\circ} \mathrm{F} .\left(40^{\circ} \mathrm{C}\right.$. $)$, two hours at I05. $8^{\circ} \mathrm{F}$. $\left(4 \mathrm{I}^{\circ} \mathrm{C}\right.$.) and one hour at $\mathrm{I06} \cdot 7^{\circ} \mathrm{F}$. $\left(4 \mathrm{I} \cdot 5^{\circ} \mathrm{C}\right.$.) were required to render infective material innocuous to other rabbits.

Levaditi and de Rothschild ${ }^{\mathbf{1 6}}$ carried out somewhat similar experiments in which thermocouples were used to determine local temperature, with less constant results. In many of the rabbits rapid healing of the primary lesions, disappearance of spirochetes, sterilisation of lymph glands and negative serologic reactions occurred. Levaditi regards artificial fever as an effective factor in stimulating the defence mechanism. Kolmer and Rule ${ }^{17}$ demonstrated that the testicular lesions were prevented and the inguinal lymph glands became sterile if rabbits inoculated intratesticularly with Spirochata pallida four days previously were immersed in water at $I I 3^{\circ} \mathrm{F}$. $\left(45^{\circ} \mathrm{C}\right.$.) for twenty minutes daily for fifteen days. If, however, the testicular lesions were kept out of the heated water, active syphilitic lesions developed. These authors 18 also found that fever of from $2^{\circ}$ to $5^{\circ} \mathrm{F}$. $\left(\mathrm{I} \cdot \mathrm{I}^{\circ}-2 \cdot 8^{\circ} \mathrm{C}\right.$. $)$ which lasted several hours and which was induced in the rabbit by intravenous injections of increasing amounts of typhoid-paratyphoid vaccine or Coley's fluid shcwed much less effect on the course of acute testicular syphilis than did fever induced by hot baths.

We have confirmed the observations of Carpenter, Boak and Warren by a somewhat different experiment. Six male rabbits were inoculated intratesticularly with fresh testicular extract containing the Nichols strain of Spirochata pallida. Only rabbits with negative Kahn 


\section{ARTIFICIAL FEVER THERAPY}

and Kolmer serologic reactions were selected. Chancres or syphilomas developed in both testes of all the animals within four to six weeks. Aspiration revealed the presence of spirochetes in all. The serologic reactions of all were strongly positive at the end of eight weeks. Hemicastration of each rabbit was then done. The testicular emulsion derived from the extirpated testis of each of these six rabbits was then injected into the testes of each of a new series of six sero-negative normal rabbits ; all developed chancres and positive serologic reactions in the usual time. Immediately after hemicastration, the syphilitic rabbits were subjected individually to sustained rectal temperature of from I07 $\cdot \mathrm{I}^{\circ}$ to $\mathrm{I08} \cdot \mathrm{I}^{\circ} \mathrm{F}$. $\left(4 \mathrm{I} \cdot 8^{\circ}-42 \cdot 4^{\circ} \mathrm{C}\right.$. $)$, average IO $7 \cdot 6^{\circ} \mathrm{F}$. $\left(42^{\circ} \mathrm{C}\right.$. $)$ for six hours, 30-metre waves of a high frequency oscillator being used. The remaining testis was then removed from each rabbit four days after the fever treatment. Injection of testicular suspensions from each heated rabbit was made into the testes of each of a new series of sero-negative normal rabbits; none developed evidence of syphilis; the serologic reactions of all remained negative.

It is quite conceivable that the same uniformity in results might not obtain following the application of fever therapy to human subjects. Syphilis in rabbits apparently pursues a somewhat milder course ; generalised lesions and central nervous system involvement are comparatively rare. Nevertheless, these experimental studies provide incontrovertible evidence of the spirochetocidal effect of sustained high-body temperature. Many observers are convinced that fever therapy is capable of producing a distinctly favourable influence on the progress of early syphilis, particularly when fever therapy is combined with orthodox chemotherapy. Kyrle ${ }^{6 c}$ gave 232 seropositive patients with early syphilis (under two years' duration) a course of arsphenamine (from 4 to $6 \mathrm{gm}$.), followed by malaria therapy (Io chills), followed in turn by another course of arsphenamine therapy. The results were incomparably better than by any other method employed. Of the 232 seropositive patients with early syphilis, the blood serologic reactions were favourably influenced in 230 (99. I per cent.) after a single combined arsphenamine-malariaarsphenamine course. Fifty-four of these patients had exhibited positive spinal fluid reactions. All were reversed 


\section{BRITISH JOURNAL OF VENEREAL DISEASES}

to negative and remained negative. When Matuschka and Rosner ${ }^{6 \mathrm{~d}}$ reported on the work of Kyrle after his untimely death, not one of these patients had relapsed, clinically or serologically, during five years of observation.

In the introduction to the Matuschka-Rosner monograph ${ }^{6 \mathrm{~d}}$, Finger makes this statement: "The results are significant. They show that in the early period of syphilis nothing influences the serum and spinal fluid reactions so favourably as combined malaria-arsphenamine therapy, that a single course is usually sufficient and that the earlier the treatment is begun, the better are the results."

Kemp and Stokes ${ }^{19}$ found that fever therapy induced by bacterial proteins, combined with arsphenamine therapy and followed by arsphenamine and bismuth therapy, offered a more satisfactory outlook in the treatment of early syphilis than routine chemotherapy alone.

Richet and Dublineau ${ }^{20}$, after experimentation with animals and human subjects, conclude that early syphilis may be "cured" more rapidly and more certainly by combined fever and chemotherapy than with chemotherapy alone. The blood serologic reactions of 35 of 37 patients with primary and secondary syphilis became negative during or at the end of one course of pyretochemotherapy.

Wagner-Jauregg ${ }^{6 b}$, O'Leary ${ }^{21}$, Jacobs and Vohwinkel ${ }^{22}$, Bering ${ }^{23}$ and others have repeatedly emphasised that the best form of treatment of neuro-syphilis lies in its prevention by combined fever and chemotherapy during its asymptomatic phase. The extensive co-operative clinical studies carried out by Stokes, Cole, Moore, O'Leary, Wile, Clark, Parran and Usilton ${ }^{24}$ reveal that abnormal spinal fluid conditions were present in 33 per cent. of patients with early syphilis, and in $56 \cdot \mathrm{I}$ per cent. of patients with late secondary syphilis. The same observers have also stated that " even thorough-going (chemical) treatment does not necessarily prevent the development of abnormalities of the spinal fluid" 24b and that in latent syphilis " almost all of the serologic response to be expected occurs within the first four months of treatment; thereafter further (chemical) treatment has little effect. ${ }^{24 c}$ "

On the basis of the foregoing observations it seems 


\section{ARTIFICIAL FEVER THERAPY}

logical to conclude that the best results are obtained when combined fever and chemotherapy are applied early in the disease. With the hope that the disastrous late neurologic, cardiovascular and visceral manifestations of the disease might be prevented, we have subjected 3 I patients with primary and early secondary syphilis to the combined fever and chemotherapy regimen [fifty hours of sustained rectal temperature between I0 $5^{\circ}-106^{\circ} \mathrm{F} .\left(40 \cdot 6^{\circ}-4 \mathrm{I} \cdot \mathrm{I}^{\circ} \mathrm{C}\right.$. $)$ and thirty injections of anti-syphilitic chemotherapy]. None had received any previous treatment for syphilis. As a control measure, 6 patients with primary or early secondary syphilis were treated with only fifty hours of fever therapy at $105^{\circ}-$ I06 $6^{\circ} \mathrm{F} .\left(40 \cdot 6^{\circ}-4 \mathrm{I} \cdot \mathrm{I}^{\circ} \mathrm{C}\right.$.). In two of these patients clinical relapse (cutaneous eruption) occurred following the fever treatments; chemotherapy was promptly instituted. Of the four patients who have had fever therapy alone, the Kahn serologic reactions became less positive in all ; the spinal fluid Kahn reactions remained negative in all.

A second control group of I9 patients with primary or early secondary syphilis received thirty weekly injections of chemotherapy, without fever therapy. Clinical evidence of relapse (cutaneous eruption) occurred in 4 patients; fever therapy was then given, with prompt remission of the skin lesions. Of the I5 patients who received only chemotherapy, the Kahn serologic reactions were reversed to negative in Io, became less positive in 4, and became more positive (Kahn quantitative reaction) in $\mathrm{I}$. The spinal fluid Kahn reactions remained negative in 13 and were reversed to negative in 2 .

Including the 6 patients who were transferred from the two previous control groups, 3I patients with primary or early secondary syphilis were treated with combined fever and chemotherapy. The cutaneous manifestations of the disease, including the chancres, responded with surprising promptness. No living, motile spirochetes were found in any of the primary lesions after the first fever treatment. The Kahn serologic reactions were reversed to negative in I7, became less positive in II, and remained negative in 3 . Of the II patients whose serologic reactions became less positive, ro have been under observation for only six to nine months. Progressive decline in the intensity of the serologic reactions, as measured by the Kahn quantitative procedure, has 


\section{BRITISH JOURNAL OF VENEREAL DISEASES}

occurred in all. The spinal fluid Kahn reactions remained negative in twenty-six instances, and were reversed to negative in five. There has been no evidence of clinical or serologic relapse in the patients treated with combined fever and chemotherapy.

With due regard to the small number of patients and the short interval of observation, these findings provide suggestive evidence that fever therapy alone or chemotherapy alone (as applied to these patients) is often inadequate. These observations also suggest that combined fever and chemotherapy is a distinctly advantageous form of treatment for early syphilis, particularly in those patients who do not respond promptly to orthodox chemotherapy. It must be appreciated that this is strictly a preliminary report of the response of early syphilis to combined fever and chemotherapy. Every effort will be exerted to follow the progress of these patients, and others who follow, throughout their lifetime.

Under existing circumstances, strong forces operate to keep the patient with early syphilis from receiving adequate treatment. It requires about eighteen months of continuous therapy in cases of early syphilis and an indefinitely longer period for the treatment of late syphilis. ${ }^{25}$ The high cost and inconvenience to the patient often result in inadequate treatment. More than a million persons seek authorised medical treatment for syphilis in the United States each year. Eighty-four per cent. of the patients treated for early syphilis in five of the large clinics devoted to syphilis, failed to remain under treatment until the disease was rendered non-infectious. Usilton ${ }^{26}$ has indicated that nearly two million persons in the United States are either inadequately treated or failed to receive any treatment for syphilis each year. Usilton has stated that: "Syphilis as a treatment problem ranks first among the contagious diseases of man."

Any method that would appreciably decrease the time and expense involved in providing adequate therapy is worthy of thoughtful consideration. A growing body of evidence appears to indicate that artificial fever therapy fortifies and intensifies the curative action of chemotherapeutic agents. The advent of simpler and safer methods for the induction and maintenance of artificial fever should stimulate vigorous investigation of this possibility. 


\section{ARTIFICIAL FEVER THERAPY}

\section{NEURO-SYPHILIS}

Dementia Paralytica.-Twenty-seven patients with dementia paralytica have completed the course of fifty hours of fever therapy plus thirty injections of chemotherapy. Twenty-one (77 per cent.) have experienced clinical remission; 3 additional patients have been restored to a working status. Two patients were accorded 50 per cent. clinical improvement; one demented patient obtained no improvement. Clinical relapse has not occurred in any case in which remission occurred. Eight of these patients were committed to a local hospital for the mentally diseased, and were brought to the Miami Valley Hospital for treatment. Sixteen of the 27 patients had received presumably adequate chemotherapy ; 2 had relapsed after receiving malaria therapy ; 9 had received no treatment.

The Kahn serologic reactions were reversed to negative in 7 , became less positive (Kahn quantitative procedure) in $\mathrm{I} 7$, and remained positive in 3. The spinal fluid Kahn reactions were reversed to negative in 6 , became less positive in $\mathrm{I} 5$, and remained positive in 6 . The level of the colloidal gold reaction was reduced in I9, elevated in 5 , changed to negative in 2 , and remained unchanged in I. The spinal fluid protein content was reduced to approximately normal levels in $\mathrm{I}_{5}$, was elevated slightly in 5 , remained normal in 4 , and was unchanged in 3 . The spinal fluid cell count was either reduced to or remained within normal limits in all.

As with fever therapy induced with malaria, there is no parallelism between the immediate clinical response and the serologic or colloidal gold reactions. In most instances the serologic reactions become less positive or negative during a period of several months following the combined chemopyretotherapy.

Neymann and Osborne ${ }^{27}$ have added to their own favourable experiences the observations of other workers in the application of artificial fever therapy by physical means to patients with dementia paralytica. Of 544 patients with dementia paralytica in all stages of the disease, I6I (30 per cent.) obtained complete clinical remission, while I55 (29 per cent.) were distinctly improved. Of 40 patients with dementia paralytica treated by electropyrexia, Neymann and Osborne 


\section{BRITISH JOURNAL OF VENEREAL DISEASES}

obtained complete remission in 25 (62 per cent.), and 4 additional patients were improved.

Tabes Dorsalis.-Fourteen patients with tabes dorsalis received the course of fever-chemotherapy. All had received presumably adequate chemotherapy; 3 had received malaria therapy followed by a temporary remission. Ataxia (in II patients) and lancinating pains or gastric crises (in I3 patients) were the chief complaints. Two patients with ataxia of three months' duration in one case, and of two years' duration in the other, were restored to normal gait ; 5 patients obtained 75 per cent. improvement in gait ; 2 obtained 50 per cent. improvement in gait; and 2 obtained no improvement in gait. There appeared to be a direct relationship between the degree of improvement and the duration of the gait disturbance.

The root pains were abolished in all. Often the pains disappeared after the first two or three treatments. Recurrence of root pains occurred in 3 patients after the usual course of treatment; these patients required additional treatments to control the pains. Normal function was restored in 2 cases of urinary and fecal incontinence.

The Kahn serologic reactions were reversed to negative in 4 patients, became less positive in 3 , remained negative in $\mathrm{I}$, and remained positive in 6 . The spinal fluid Kahn reactions were reversed to negative in 3 , became less positive in 4 , remained positive in 3 , and remained negative in 4 .

Tabetic Form of Dementia Paralytica.-Eight patients with the tabetic form of dementia paralytica were subjected to the combined treatment. All had previously received chemotherapy without influence upon the course of the disease; 2 had also received malaria therapy, followed by remissions, lasting six months in one instance and one year in the other. Improvement in mental orientation occurred in 6 ; two demented patients died, one seven months after the treatment was completed, the other fifteen months following the treatment. Subsidence of root pains occurred in all; in two instances additional fever treatments were required. Improvement in gait occurred in 4 of 5 patients with ataxia ; I patient who had had a tabetic gait for three months was restored to normal gait. One patient with a "cord bladder" regained normal control of bladder function. 


\section{ARTIFICIAL FEVER THERAPY}

The Kahn serologic reactions were reversed to negative in two instances, became less positive in two, remained negative in three, and remained positive in one. The spinal fluid reactions were reversed to negative in four, became less positive in three, and remained positive in one.

Diffuse Central Nervous System Syphilis.-In this group are placed 23 patients with various manifestations of symtomatic neuro-syphilis, which could not be difinitely classified as dementia paralytica, tabes dorsalis or the tabetic form of dementia paralytica. Nineteen of these patients had received presumably adequate chemotherapy; 4 patients had received no chemical therapy. There were 8 cases of congenital syphilis and I5 cases of acquired syphilis. Included in this series are 16 cases in which symptoms and signs of exudative ocular syphilis predominated. Two patients had experienced hemiplegia following cerebral thrombosis; fever therapy exerted very little influence upon the residual effects of the hemiplegia. Among the 23 patients of this group, I6 patients obtained symtomatic relief ; 5 were moderately improved; 2 obtained no improvement. The Kahn serologic reactions were reversed to negative in 4, became less positive in $\mathrm{I} 4$, remained positive in 3 , and remained negative in 2 . The spinal fluid Kahn reactions were reversed to negative in 6 , became less positive in 3 , remained positive in 3 and remained negative in II.

Asymptomatic Neuro-syphilis.-Of 7 patients with asymptomatic neuro-syphilis, all of whom had received apparently ineffectual chemotherapy, the spinal fluid Kahn reactions were reversed to negative in all. The $\mathrm{Kahn}$ serologic reactions were reversed to negative in 4 , remained negative in 2 , and became less positive in $\mathrm{I}$. None has shown evidence of serologic relapse.

\section{OCULAR Syphilis}

Ocular complications ${ }^{28}$ existed in 58 of the syphilitic patients, including 4 patients with double classification (conjugate palsy and optic atrophy, uveitis and optic atrophy, uveitis and neuro-retinitis, and neuro-retinitis and choroiditis). The ocular complications may be classified as follows :- 


\section{BRITISH JOURNAL OF VENEREAL DISEASES}

(I) Extraocular palsies . . . . . 4

(2) Interstitial keratitis . . . . . II

(3) Exudative uveitis . . . . IO

(4) Optic neuritis and neuro-retinitis . . I4

(5) Choroiditis .

(6) Optic atrophy . . . . . . . . I6

In the evaluation of the response of 4 patients with extraocular palsies to artificial fever therapy there was no evidence that this method is superior to older forms of treatment.

Among the II patients with interstitial keratitis were 8 who had experienced recurrences and Io who had failed to respond to chemotherapy. The duration of the disease and the tendency towards recurrence appear to be distinctly lessened following adequate fever therapy combined with chemotherapy. The response is most prompt in those cases in which an opaque central disc of plastic exudate exists. It is usually this type of the disease which produces the greatest visual damage.

In Io cases of exudative uveitis prompt clinical improvement became apparent in every instance after the first one or two fever treatments. With the exception of I patient who had advanced old degenerative changes, all have recovered useful vision. One patient experienced a mild recurrence, probably because of inadequate fever therapy. With due regard to the small number of cases in this series, the results were so uniformly favourable that we regard combined fever-chemotherapy as the treatment of choice in syphilitic exudative uveitis.

Favourable response occurred in the lesions of $\mathrm{I}_{4}$ patients with optic neuritis and neuro-retinitis. All recovered useful vision although 9 have some residual pallor of the disc and some degree of field contraction. Active neuritis along the optic tract appears to be arrested by fever therapy.

Active choroiditis in 7 patients subsided with fever therapy with residual scars and field defects. Good central vision has resulted in all but one eye.

In I6 patients with optic atrophy the visual acuity and visual fields remained practically unaltered after a course of combined fever-chemotherapy. If optic atrophy is 


\section{ARTIFICIAL FEVER THERAPY}

associated with foci of active infiltration along the optic tract, it is quite probable that such exudative lesions will respond to fever therapy. Optic atrophy is not a contraindication to fever therapy.

From these observations it seems quite apparent that artificial fever therapy is most effective in the exudative lesions of ocular syphilis, and that the best results are obtained when pyretochemotherapy is instituted promptly after the first appearance of the exudative lesions.

\section{Resistant Sero-Positive Syphilis}

Included in this study were Io patients with so-called "Wassermann-fast" syphilis, or what we prefer to term resistant sero-positive syphilis. All had had presumably adequate chemotherapy for at least two years. The Kahn serologic reactions were reversed to negative in 5 , became less positive in 4 , and remained positive in one. The spinal fluid Kahn reactions remained negative in all. Serologic relapse has not occurred in any of these patients.

\section{TReatment of Gonococcic Infections}

It has long been known that Neisseria gonorrhee is a particularly thermolabile organism. There are many records of spontaneous recovery or remissions from the manifestations of gonococcic infections during intercurrent febrile disease. It is also well known that the gonococcus soon disappears and is replaced by secondary invaders when it reaches deep tissues, such as the fallopian tubes. Neisser and Scholtz ${ }^{29}$ found it difficult to cultivate the gonococcus in patients with fever. Bacteriologists have recognised that the organism does not grow well on artificial mediums at temperatures of $100 \cdot 4^{\circ} \mathrm{F}$. $\left(38^{\circ} \mathrm{C}\right.$.) or above.

The recognition that fever exerts a favourable influence upon gonorrhœa and its complications has led to treatment with fever produrced by malaria inoculation or with chemical or foreign protein substances. While some satisfactory clinical results have been obtained by such methods, they have the drawback of being inconstant in their fever-producing properties and frequently provoke serious, uncontrollable, and occasionally fatal, reactions. Localised fever treatments have been carried out, for the most part with high frequency electric currents such as 


\section{BRITISH JOURNAL OF VENEREAL DISEASES}

diathermy or radiothermy. The chief objection to this procedure is that the heat treatment is limited to a localised area. Patients with gonococcic arthritis are suffering from a systemic disease, requiring systemic treatment.

The indefinite, and often contradictory, reports of the thermal death time of Neisseria gonorrhea have been clarified by the extensive thermal death-time gradient studies made recently by Carpenter, Boak, Mucci and Warren. ${ }^{30}$ When it became apparent that gonococcic infections responded to artificial fever therapy if the fever was sustained for long periods at a high level, these workers set out to determine the thermal death-time gradient of the gonococcus when subjected to temperatures that can be tolerated by man. The in vitro thermal death time of fifteen strains of Neisseria gonorrhea was determined at different temperature levels. Some of the strains had been under artificial cultivation for many years, while others had been isolated one to four months previously. At $102 \cdot 2^{\circ} \mathrm{F}$. $\left(39^{\circ} \mathrm{C}\right.$.) growth was not appreciably affected. At $104^{\circ} \mathrm{F} .\left(40^{\circ} \mathrm{C}\right.$.) about 99.7 per cent. of the organisms were killed by ten hours' exposure. At I05. $8^{\circ} \mathrm{F}$. $\left(4 \mathrm{I}^{\circ} \mathrm{C}\right.$.), 99 per cent. of the gonococci were destroyed in from four to five hours' exposure; the remaining I per cent. required eleven to twenty-three hours. At I06. $7^{\circ} \mathrm{F}$. $\left(4 \mathrm{I} \cdot 5^{\circ} \mathrm{C}\right.$. $)$ and $107 \cdot 6^{\circ} \mathrm{F}$. $\left(42^{\circ} \mathrm{C}\right.$. $)$, 99 per cent. of the gonococci were rendered non-viable in two hours, while the remaining I per cent. required five to twenty hours. The cultures which had been under cultivation for only a short period were most susceptible to heat. From these studies it became apparent that it would be possible, in most instances, to exceed the thermal death time of the organism without injury to the human host, by adapting the temperature level in patients with gonococcic infections to the thermal death time of the organism. We have repeated the experiments of Carpenter, Boak, Mucci and Warren with essentially identical results.

There is, therefore, convincing evidence, based upon in vitro thermal death-time studies and the clinical response of patients with gonococcic infections to artificial fever therapy, that it is possible, in most instances, to destroy gonococci in the various lesions of the disease with high sustained body temperature. In addition to 


\section{ARTIFICIAL FEVER THERAPY}

this sterilising effect, there is also evidence which indicates that artificial fever therapy stimulates immune reactions. In 4 of our patients with gonococcic urethritis, gonococci were present after four fever treatments. The organisms disappeared in from two to four weeks in these patients, providing evidence that the stimulus to immune reactions produced by fever was responsible for the ultimate disappearance of the gonococci. Carpenter, Boak and Warren ${ }^{3 i}$ have suggested that the duration of the fever treatment should be based upon the thermal death time of the strain of gonococcus responsible for the disease in each individual patient. They subjected II patients to a single fever treatment at $106 \cdot 7^{\circ} \mathrm{F}$. $\left(4 \mathrm{I} \cdot 5^{\circ} \mathrm{C}\right.$.), equal in length to the thermal death time (five to seventeen hours) of the cultures obtained from individual patients, following which there was a prompt disappearance of the gonococci and all clinical evidence of the disease. Similar results were obtained in 9 patients when the fever period was one-fourth to three-fourths of the thermal death time, suggesting the assistance of the defence factors in the body in the disappearance of the disease. In practice we have found important objections to such a plan. It sometimes requires several days to carry out accurate thermal death-time determinations. Occasionally the organism is recovered with difficulty. Individual patients may harbour multiple strains, which differ in their heat resistance. In rare instances, highly resistant strains require twenty or more hours at temperatures of $107^{\circ} \mathrm{F}$. $\left(4 \mathrm{I} \cdot 7^{\circ} \mathrm{C}\right.$.) or above before they are destroyed.

For practical purposes we have found that four or five treatments, each of five to seven hours' duration, at a rectal temperature range of $106^{\circ} \mathrm{F}$. $\left(4 \mathrm{I} \cdot \mathrm{I}^{\circ} \mathrm{C}\right.$.) to $107^{\circ} \mathrm{F}$. $\left(4 \mathrm{I} \cdot 7^{\circ} \mathrm{C}\right.$.), at intervals of three to five days, are productive of prompt and satisfactory results in the great majority of cases. Early in the course of this undertaking it was our practice to give the treatments at intervals of one week or longer. The more promptly favourable results obtained by Desjardins, Hench, Stuhler and Popp ${ }^{32} 33 \quad 34$ convinced us of the necessity for altering our technique by giving the treatments at shorter intervals. The average interval between treatments during the first part of our work was six (6.I4) days. During the past two years the average interval between treatments has 


\section{BRITISH JOURNAL OF VENEREAL DISEASES}

been four $(4 \cdot 07)$ days. The average number of treatments was approximately five $(4 \cdot 9)$. Four treatments at intervals of three to five days, the interval depending upon the general condition of the patient and his tolerance of the treatments, are usually regarded as a minimum course. If all evidence of activity, in either the joints or the genito-urinary tract, has not disappeared, additional treatments are given at equivalent intervals.

\section{Gonococcic Arthritis}

One of the most frequent and disabling complications of gonorrhœa is gonococcic arthritis. In a high proportion of cases permanent deformity and disability, affecting one or several joints, is the end result. The fact that so many different methods of treatment have been employed provides evidence of the inadequacy of most or all of them.

During the past three years the outlook for patients with gonococcic arthritis has been enormously improved. In March, I932, a thirty-nine-year-old man was referred to us for artificial fever therapy because of resistant sero-positive syphilis. The history and physical examination revealed that the patient also had active chronic gonococcic arthritis of five months' duration, involving the right wrist. Gram-negative intracellular diplococci were found in large numbers in urethral smears. After the third artificial fever treatment, each of which consisted of five hours of fever above $105^{\circ} \mathrm{F} .\left(40 \cdot 6^{\circ} \mathrm{C}\right.$.) at intervals of one week, all evidence of active gonococcic arthritis had disappeared. The joint function, which had been practically nil, was restored to 90 per cent. of normal. The urethral smears became negative for gonococci after the fourth treatment, and have remained negative since that time. Encouraged by this coincidental observation we decided to treat other cases of gonococcic arthritis.

Scattered reports ${ }^{35-44}$ of favourable experiences in the treatment of gonococcic arthritis with artificial fever therapy have appeared in medical literature since I932. The results obtained with a variety of physical modalities have been summarised and tabulated in a recent communication by Hench, Slocumb and Popp. ${ }^{33}$ Of 33 cases mentioned in the nine reports reviewed by these authors, data on the results obtained in the treatment of 24 patients 


\section{ARTIFICIAL FEVER THERAPY}

could be calculated. Of these 24 patients, 22 (92 per cent.) were " completely relieved " or " cured." Failure resulted in only 2 cases ( 8 per cent.) and was attributed to inadequate fever production. Hench, Slocumb and Popp have treated 16 patients suffering from gonococcic arthritis with artificial fever therapy, utilising the Kettering hypertherm. Nine of the patients had acute arthritis, while 7 had the disease in a chronic form. Eighty-eight per cent. of the patients with acute gonococcic arthritis were promptly " cured," or practically so, while the remaining I2 per cent. obtained marked improvement. Of the 7 patients with chronic gonococcic arthritis, all but one were markedly improved. The authors state: "In gonococcic arthritis, results are so striking and apparently so superior to those obtained by other methods, that we can prescribe fever therapy as the method of choice with considerable assurance."

Schnabel and Fetter ${ }^{45}$ have reported their experiences in the treatment of 18 patients with gonococcic arthritis, also utilising the Kettering hypertherm. Of the 9 patients with the acute form of the disease, 6 were cured, 2 obtained marked improvement and I inadequately treated patient received moderate improvement. Five of the 9 patients with chronic gonococcic arthritis (of more than six weeks' duration) wєre cured, 3 were markedly improved, while I received only moderate improvement.

Anderson, Arnold and Trautman ${ }^{46}$ and Faget 47 of the United States Public Health Service (Marine) Hospitals at New Orleans and Norfolk, treated 24 patients with gonococcic arthritis; all but 2 were cured with one to seven treatments; the remaining 2 patients received distinct benefit.

We have completed the course of treatment of 45 patients with gonococcic arthritis. Thirty-one were suffering with the acute form of the disease (less than eight weeks' duration), while I4 had chronic gonococcic arthritis. The patients were not selected. The only requirements were that a diagnosis of gonococcic arthritis could be established and that the physical condition of the patient would permit him to tolerate the treatments. Contrary to common belief, multiple joints were usually affected. In 32 of the patients (7I per cent.), the disease was polyarticular. Thirty-two of the 45 patients had 


\section{BRITISH JOURNAL OF VENEREAL DISEASES}

received some form of local chemical treatment of the genito-urinary tract before the onset of arthritis. In the male patients this usually consisted of the installation of a silver preparation into the urethra. At the time of the diagnostic survey, prior to the institution of fever therapy, the urethral or cervical smears of 32 patients revealed the presence of Gram-negative intracellular diplococci. Of the 13 patients with negative smears, all had had positive smears just prior to the time of their admission to the Miami Valley Hospital. In no case was the infection restricted to the anterior urethra in the male. Of the Io female patients there were 2 with pelvic cellulitis, one with urethritis and Bartholinian abscess, and 7 with acute cervicitis. Of the 7 with acute cervicitis, 2 had urethritis, I had urethritis and bilateral salpingitis, I had bilateral salpingitis, and I had bilateral salpingitis and left tubo-ovarian abscess. Following the course of fever therapy for the treatment of gonococcic arthritis, all evidence of gonococcic infection of the genito-urinary tract had disappeared in 38 patients ( 84 per cent.). Of the 7 patients with persistence of genito-urinary gonococcic infection, all evidence of the disease disappeared in 4 patients within two to four weeks without additional fever or local treatments. Two of the remaining patients with persistent genito-urinary infection had received inadequate fever therapy (less than three treatments); the third had received apparently adequate fever therapy (five treatments), but the urethral smears remained positive. Supplemental local treatment eliminated all evidence of gonococcic infection of these three refractory patients.

Of the 3I patients with acute gonococcic arthritis, the average improvement in joint function immediately following the conclusion of the course of fever treatments was 80 per cent. ; in Io patients the restoration of joint function was complete. At the time of writing; the average improvement in joint function in the $3 I$ acute cases is 99.7 per cent. ; 29 of the patients with acute gonococcic arthritis now have complete restoration of joint function. Of the I4 patients with chronic gonococcic arthritis, the average improvement immediately following the course of fever therapy was $66 \cdot \mathrm{I}$ per cent. Of the I4 patients with chronic gonococcic arthritis, the average improvement at the time of writing is 92.8 per 


\section{ARTIFICIAL FEVER THERAPY}

cent. ; 7 patients have obtained complete restoration of joint function.

Worthy of particular mention are our experiences with 2 cases of chronic gonococcic arthritis, in which almost complete limitation of motion of one knee joint remained after the usual course of fever therapy. After all evidence of active inflammation had disappeared the joints were manipulated under general anæsthesia (brisement forcé) in order to separate the fibrous adhesions. Fever therapy was immediately instituted following the surgical manipulation. In both cases practically complete joint function has been restored. Orthopædic management is a requirement in those cases of chronic gonococcic arthritis in which partial ankylosis has occurred prior to the institution of fever therapy.

\section{Gonococcic Infections, other than ARThritis}

The distinctly favourable experiences of Desjardins, Stuhler and Popp, ${ }^{32}{ }^{34}$ Bierman and Horowitz, ${ }^{48}$ Carpenter, Boak and Warren, ${ }^{31}$ Anderson, Arnold, Trautman and Faget, $\mathbf{4 6}^{\mathbf{4 7}}$ have provoked a lively interest in the fever therapy of gonococcic urethritis, cervicitis, vaginitis, salpingitis, prostatitis, seminal vesiculitis, epididymitis, oph thalmia, and dermatitis blennorrhagicum. Desjardins et al., subjected 76 patients with simple or complicated gonococcic infection to fever therapy in the Kettering hypertherm; of these, $68(89.5$ per cent.) were cured, and the condition of $7(9.2$ per cent.) was improved; in only I patient did the infection prove refractory to fever treatment. The average number of treatments was six. In a report of the progress of these patients, Stuhler ${ }^{\mathbf{4 9}}$ stated: "I believe that the introduction of fever therapy for gonococcic infections is one of the greatest advances made in the last fifty years. I believe it is of even greater importance to the clinician than was the discovery of the gonococcus by Neisser in I879." Bierman and Horowitz ${ }^{48}$ have achieved excellent results by an ingenious combination of systemic hyperpyrexia (IO5 I0 $7^{\circ} \mathrm{F}$.; $40 \cdot 6^{\circ}-4 \mathrm{I} \cdot 7^{\circ} \mathrm{C}$.) with simultaneous additional heating of pelvic structures (to $\operatorname{III}{ }^{\circ}-\mathrm{II} 2^{\circ} \mathrm{F}$.; $43 \cdot 8^{\circ}-$ $444^{\circ} \mathrm{C}$.) by diathermy electrodes especially adapted to the vagina or rectum.

We have treated 28 patients with gonococcic infection, 


\section{BRITISH JOURNAL OF VENEREAL DISEASES}

other than gonococcic arthritis. There were 23 men and 5 women, whose ages ranged from eighteen to fifty-eight years. Eighteen were suffering with the acute form and Io with the chronic form of the disease. Eighteen patients (64 per cent.) had received some form of local chemical treatment of the genito-urinary tract prior to the institution of artificial fever therapy. Eight patients with acute gonococcic urethritis had received orthodox local treatment for an average of five weeks prior to fever therapy; the ro patients with chronic gonococcic urethritis had received local treatment for from two months to five years.

The average interval between the onset of gonorrhœa and the institution of fever therapy was twenty-four days in the acute cases ; in 7 of the chronic cases the average interval was seven and a half months, while the interval was from four to seven years in the remaining 3 cases.

Only one of the male patients had simple acute anterior urethritis ; in all of the others there was extension to the posterior urethra, prostate, seminal vesicles or epididymis. In none of the 5 female patients was the infection localised to the urethra or cervix. All had pelvic cellulitis, while one had associated Bartholinian and bilateral tuboovarian abscesses.

The average number of treatments given to the 28 patients was 3.32 ; approximately the same number of treatments were given to patients with either the acute or chronic form of the disease.

The average interval in the treatment of the first I9 patients was 6.58 days. After we had learned that favourable results were more prompt and uniform when the interval between treatments was shortened, we altered our programme. The last 9 patients to be treated received an average of 3.5 treatments at an average interval of three days.

At the conclusion of the course of fever therapy all evidence of gonococcic urethritis and its complications had disappeared in 25 (89 per cent.) of the 28 patients. No other form of treatment was employed in these patients. In I patient gonococcic ophthalmia responded to the first treatment. In 2 patients with dermatitis blennorrhagicum, the skin lesions disappeared after one treatment in I case and after two treatments in the other. Two male patients and I female patient, treated at I58 


\section{ARTIFICIAL FEVER THERAPY}

irregular and long intervals (seven to fourteen days), had persistently positive smears or cultures. All received apparently inadequate fever therapy (two treatments in 2 cases and three treatments in the third). In the female patient, who had acute gonococcic cervicitis and bilateral salpingitis, the pelvic complication disappeared after fever therapy, but positive cervical smears remained. After additional local treatment the smears of all three became negative within two weeks.

\section{Comment}

With two exceptions all of the persons with syphilis were treated as ambulatory patients. During the past year we have found that it is distinctly advantageous to admit patients with gonococcic infections to the hospital for a period of two weeks. We have found this to be particularly desirable in cases of gonococcic arthritis. This plan permits close supervision of the patient and eliminates the unco-operative patient.

Artificial fever therapy by physical means is not a simple undertaking. In the hands of unskilled or unscrupulous persons it is fraught with danger. History is repeating itself in the attempts of certain manufacturers to exploit the field by utilising modern high-pressure sales methods. Some of the apparatus now available through commercial sources is inadequate and dangerous, and is sold to any physician without thought of adequate training of the supervising physicians and his technical assistants. Three important considerations are involved in the proper application of artificial fever therapy. The first is the thorough training of the supervising physician in the physical and the physiologic aspects of the undertaking. The second is the adequate training of the nursetechnicians. The third, and perhaps the least important consideration, is the apparatus. The undertaking is in many respects comparable to a major surgical operation, particularly as regards the necessity for a careful diagnostic survey to determine eligibility and the constant attention to the patient by physician and nurse-technician during the long treatment. It is well to re-emphasise the obvious but too often disregarded fact, that skill of personnel far transcends in value the perfection of matériel. The nurse-technician should receive at least 


\section{BRITISH JOURNAL OF VENEREAL DISEASES}

one to two months of special training before undertaking this work. Exceptional alertness and intelligence are primary qualifications.

It seems quite apparent that artificial fever therapy by physical means should be restricted to institutions in which the physician and nurse personnel has received adequate preliminary training. The production of effectual artificial fever is not adaptable to ordinary office practice. Unless these precautions are exercised this important adventure in therapeutics is almost certainly doomed to a period of discredit not unlike that which followed the introduction of Roentgen rays. In the hands of skilled and devoted workers this form of therapy seems destined to occupy an increasingly important place in therapeutics.

\section{Summary AND Conclusions}

(I) The value of artificially induced fever therapy as an adjunct to chemotherapy in the management of neurosyphilis is now firmly established. The one factor common to the wide variety of infections, chemical and physical methods that have yielded comparable therapeutic results appears to be simple fever production.

(2) A simplified, controlled and relatively inexpensive method for fever induction and maintenance (Kettering hypertherm) has been devised. High frequency electric currents are not employed. During the past four years, 43I patients have been subjected to 3,204 artificial fever treatments, without any serious ill-effects related to the method of treatment.

(3) The frequent observation that the best results occurred when neuro-syphilis was treated by combined fever and chemotherapy during its earliest manifestations led us to apply the treatment to patients with primary or early secondary syphilis. The results provide evidence that fever therapy may be of great value in early syphilis, particularly when chemotherapy alone appears to be inadequate.

(4) The results obtained in the treatment of symptomatic neuro-syphilis, asymptomatic neuro-syphilis, ocular syphilis, and resistant sero-positive syphilis are at least comparable, if not superior, to the results obtained with the more hazardous, time-consuming and inconstant malaria therapy. 


\section{ARTIFICIAL FEVER THERAPY}

(5) Hospitalisation is not a requirement for fever therapy by physical means.

(6) The advent of simpler and safer methods for the production of artificial fever should stimulate vigorous investigation of the possibility that the time, effort and expense involved in the adequate therapy of syphilis may be greatly lessened.

(7) There is evidence that artificial fever therapy fortifies and intensifies the action of anti-syphilitic chemotherapeutic agents.

(8) High, sustained, controlled artificial fever is the treatment of choice for gonococcic arthritis. Gonococcic arthritis is a manifestation of a systemic disease, requiring systemic treatment.

(9) In vitro thermal death-time studies, and the clinical response of patients with gonococcic infections to artificial fever therapy, indicate that it is possible, in most instances, to destroy gonococci in the various lesions of the disease with high, sustained body temperature. In addition to this sterilising effect there is evidence that artificial fever therapy stimulates immune reactions.

(I0) Forty-five patients with gonococcic arthritis, associated with gonococcic infection of the genitourinary tract, have been treated with artificial fever therapy. Of $3 \mathrm{I}$ patients with acute gonococcic arthritis, the average improvement in joint function immediately after the conclusion of the course of fever therapy was 80 per cent.; in Io patients the restoration of joint function was complete. The ultimate average improvement in joint function in the cases of acute gonococcic arthritis was 99.7 per cent.; 29 obtained complete restoration of joint function. Of the I4 patients with chronic gonococcic arthritis the average improvement in joint function at the conclusion of the course of fever therapy was 66.I per cent. ; the ultimate improvement in joint function in these cases was 92.8 per cent. ; in 7 patients all evidence of joint disease disappeared. After the course of fever therapy all evidence of genitourinary tract infection had disappeared in 38 patients. The smears and cultures of 4 additional patients became negative within two to four weeks without additional treatment of any kind. Supplemental local treatment eliminated all evidence of gonococcic infection in the 


\section{BRITISH JOURNAL OF VENEREAL DISEASES}

remaining 3 refractory patients, two of whom had received inadequate fever therapy.

(II) In two cases of chronic gonococcic arthritis almost complete limitation of motion of one knee joint remained after the course of artificial fever therapy. Orthopædic manipulation (brisement forcé) under general anæsthesia was done to separate the fibrous adhesions. Artificial fever therapy was instituted immediately following the surgical manipulation. Practically normal joint function was restored in both cases.

(I2) In 28 patients with gonococcic infection other than gonococcic arthritis, all evidence of gonococcic urethritis and its complications had disappeared in 25 (89 per cent.) at the conclusion of the course of fever therapy. The remaining 3 patients received apparently inadequate fever therapy.

(I3) It would appear that the therapeutic armamentarium of the venereologist is now provided with a new and powerful weapon.

\section{BIBLIOGRAPHY}

(I) WAgNer-JAURegG, Julius: " Uber die Einwirkung der Malaria auf die progressive Paralyse," Psychiat.-Neurol. Wchnschr., 20, pp. I32I34, August 3Ist, I9I8.

(2) ReImanN, H. A. : "Significance of Fever and Blood Protein Changes in Regard to Defence against Infection," Ann. Int. Med., 6, pp. 362-374, September, 1932.

(3) Whitney, W. R.: " Radiothermy," General Electric Rev., 35, pp. 4IO-4I2, August, I932.

Carpenter, C. M., and PAge, A. B. : " The Production of Fever in Man by Short Radio Waves," Science, 71, pp. 450-452, May 2nd, I930 ;

DE WALt, K. C. : " A Study of High Frequency Heating," Electronics 5, p. 338, I 932 .

(4) Simpson, W. M., Kislig, F. K., and Sittler, E. C. : “UltraHigh Frequency Pyretotherapy of Neurosyphilis: A Preliminary Report," Ann. Int. Med., "7, pp. 64-75, July, I933.

(5) Simpson, W. M. : "Influence of Radiotherm Pyretotherapy on Chloride Metabolism," J.A.M.A., 100, pp. 67-68, January 7th, I933.

(6) (a) WAGNER-JAUREgG, JuLIUS: "Malariatherapie," Wien. med. Wchnschr., 78, pp. 275-287, February 25th, 1928 ;

(b) WAGNER-JAUREGG, JULIUS: "Uber maximale Malariabehandlung der progressiven Paralyse," Klin. Wchnschr., 13, pp. I028-I03I, July I4th, I 934 .

(c) Kyrle, J. : "Die Malariabehandlung der Syphilis," Wien. klin. Wchnschr., 37, pp. IIO5-IIO9, October 23rd, I924.

(d) Matuschka, J., and Rosner, R.: " Die Malariatherapie der Syphilis," Vienna, Julius Springer, I927.

(e) KAuders, O.: "Uber die Nachbehandlungsperiode nach I62 


\section{ARTIFICIAL FEVER THERAPY}

Malariabehandlung der progressiven Paralyse," Wien. klin. Wchnschr., 14, pp. II99-I200, September I8th, I93I.

( $f$ ) Paige, A., Rickloff, R. J., and Osborne, E. D. : “The Treatment of Neurosyphilis, other than Paresis, with Malaria," New York State J. Med., 31, pp. I44I-I446, December Ist, I93I.

(g) Neustaedter, M. : "The Treatment of Cerebrospinal Syphilis with Malaria." A Report of Twenty-six Cases, J. Nerv. and Ment. Dis., 73, pp. 59I-599, June, I93I.

(h) Gugenheim, F. : " Das Schicksal der mit Malaria behandelten Luescerebrospinaliskranken," Ztschr. f. d. ges. Neurol. u. Psychiat., 131, pp. 525-54I, January 24th, I93I.

(i) ReEse, H. H. : " Non-specific and Malarial Therapy in Neurosyphilis,” Am. J. Syph., 13, pp. 348-359, July, I929.

(j) Solomon, H. C., and Epstein, S. H.: "Tryparsamide in the Treatment of Neurosyphilis," New York State J. Med., 31, pp. Ior2I9I5, August I5th, I93I.

(k) O'Leary, P. A., and Welsh, A. L. : "Treatment of Neurosyphilis with Malaria: Observations with Nine Hundred and EightyFour Cases in the last Nine Years," J.A.M.A., 101, pp. 498-501, August I2th, I933.

(7) Bratz, E.: " Hat sich die Malariabehandlung bei Paralyse und Tabes bewährt ?" Ztschr.f. ärztl. Fortbild., 26, pp. 560-56r, September Ist, I929.

(8) Kann, R. L. : “The Kahn Test," a Practical Guide, Williams and Wilkins, Baltimore, I928: "Serum Diagnosis of Syphilis by Precipitation," Williams and Wilkins, Baltimore, I928.

(9) Weichbrodt, R., and Jahnel, F.: " Einfluss höher Körpertemperaturen auf die Spirochäten und Krankheitserscheinungen der Syphilis im Tierexperiment," Deutsche med. Wchnschr., 45, pp. 483-484, May Ist, I9I9.

(Io) Schamberg, J. F., and Rule, Anna M. : "Studies of the Therapeutic Effect of Fever in Experimental Rabbit Syphilis," Arch. Dermat. and Syph., 14, pp. 243-255, September, I926.

(II) Schamberg, J. F., and Rule, Anna M. : " Therapeutic Effect of Hot Baths in Experimental Primary Syphilis in Rabbits," J.A.M.A., 88, pp. I2I7-I218, April I6th, I927.

(I2) Schamberg, J. F., and Rule, Anna M.: "The Effect of Extremely Hot Baths in Experimental Syphilis," Arch. Dermat. and Syph., 1\%, pp. 322-33I, March, I928.

(I3) Schamberg, J. F., and TSEng, H. W. : " Experiments on the Therapeutic Value of Hot Baths, with Special Reference to the Treatment of Syphilis." Physiologic Observations. Am. J. Syph., 11, pp. 337-397, July, r927.

(I4) Bessemans, A., De Potter, F., and Hacquaert, R. : "Sur deux formes d'aéro-thermothérapie locale des syphilomes testiculaires primaires du lapin," Compt. rend. Soc. de biol., 100, pp. 757-76o, March I5th, I929;

Bessemans, A., Vercoullie, J., and Hacquaert, R. : “ Nouvel essai de thermoprophylaxie sociale antisyphilitique : traitement aérothermique local du chancre primaire," Rev. belge sc. med., 1, pp. 425430, May, I929; "Influence de diverses applications locales de la chaleur sur les accidents syphilitiques primaires et secondaires chez l'homme," Compt. rend. Soc. de biol., 101, pp. 483-486, June I4th, I929; 


\section{BRITISH JOURNAL OF VENEREAL DISEASES}

Bessemans, A. : "The Local Application of Heat as an Adjunct in the Social and Individual Prophylaxis of Syphilis," Urol. and Cutan. Rev., 34, pp. 7I-9I, February, I930 ;

Bessemans, A., and ThIRy, U.: "New Experiences with the Application of Local Heat Therapy (Hot-water Baths and Diathermy by Long Waves Slightly Damped) in the Treatment of Primary and Secondary Syphilis in Man," ibid., 37, pp. 377-390, June, I933.

(I5) CARpenter, C. M., and BoAK, RUTH A.: " The Effect of Heat produced by an Ultra-high Frequency Oscillator on Experimental Syphilis in Rabbits," Am. J. Syph., 14, pp. 346-365, July, I930 ;

CARpenter, C. M., Boak, Ruth, A., and Warren, S. L.: "The Healing of Experimental Syphilis in Rabbits by Short Wave Fevers," J. Exper. Med., 56, pp. 75I-762, November, I932 ;

Boak, Ruth, A., Carpenter, C. M., and Warren, S. L. : "The Thermal Death Time of Treponema Pallidum in Vitro, with Special Reference to Fever Temperatures," J. Exper. Med., 56, pp. 74I-750, November, I932.

(I6) Levaditi, C., and DE Rothschild, H. : " Etude expérimentale de la thermothérapie générale par les radiations à ondes courtes," Ann. Inst. Pasteur, 52, pp. 23-67, January, I934.

(I7) Kolmer, J. A., and Rule, Anna M. : "Hot Baths in Experimental Primary Syphilis of Rabbits and in Trypanosomiasis of Rats," Arch. Dermat. and Syph., 27, pp. 660-662, April, I933.

(I8) Kolmer, J. A., and Rule, Anna M. : " Bacterial Protein Fever in the Treatment of Syphilis in the Rabbit," Arch. Dermat. and Syph., 24, pp. 546-553, October, I931.

(I9) Kemp, J. E., and Stokes, J. H. : " Fever induced by Bacterial Proteins in the Treatment of Syphilis," J.A.M.A., 92, pp. I737-I740, May 25th, I929.

(20) Richet, C., Jr., and Dublineau : "Pyréto et chimiothérapie associées dans le traitement de la syphilis du lapin," J. de physiol. et de path. gen., 31, pp. 794-8II, September, I933;

Richet, C., Jr., Dublineau, J., and Joly, F. : “ Pyréto et Chimiothérapie associées dans la syphilis primaire et secondaire: étude expérimentale et clinique," Presse med., 41, pp. r649-165I, October 25th, I933;

RicheT, C., Jr., and Dublineau, J. : “ La pyrétothérapie de la syphilis," Paris med., 1, pp. I97-205, March 3rd, I934.

(2I) O'Leary, P. A. : " Treatment of Neurosyphilis by Malaria," J.A.M.A., 91, pp. 543-545, August 25th, I928; “Treatment by Malaria in Asymptomatic Neurosyphilis, ibid., 97, pp. I585-I587, November 28th, I93I.

(22) Jacobs, J., and Vohwinkel, K. H. : “ Die Malariatherapie der Früh und Spätlues," Dermat. Ztschr., 5\%, pp. 32I-346, January, I930.

(23) BERING: "Die Malariabehandlung im Frühstadium der Syphilis des Zentralnervensystems," Zentralbl.f.Haut-und Geschlechtskr., 17, p. 4I, June 5th, I925.

(24) (a) Stokes, J. H., Cole, H. N., Moore, J. E., O'Leary, P. A., Wile, U. J., Clark, Taliaferro, Parran, Thomas, and Usilton, LidA, J. : "Co-operative Clinical Studies in the Treatment of Syphilis," Ven. Dis. Inform., 13, pp. I65-182, May 20th, I932;

(b) Ibid., 13, pp. 253-292, July 2oth, I932;

(c) Ibid., 14, pp. I-I2, January, I933. 


\section{ARTIFICIAL FEVER THERAPY}

(25) Exner, M. J.: “ The Value of Instructing the Syphilis Patient," Ven. Dis. Inform., 16, pp. 59-64, March, I935.

(26) Usilton, Lida, J. : " Trend of Syphilis and Gonorrhœa in the United States," Ven. Dis. Inform., 16, p. I47, May, I935.

(27) Neymann, C. A., and Osborne, S. L. : "The Development of Hyperpyrexia," Arch. Phys. Therap., 15, pp. I49-I55, March, I934.

(28) Culler, A. M., and Simpson, Walter M. : "Artificial Fever Therapy in Cases of Ocular Syphilis," Archives of Ophthalmology, 15, pp. 624-644, April, I936.

(29) Neisser, A., and Scholtz, W. : " Gonorrhœ, in Handbuch der pathogenen Mikroorganismen," Jena, 3, p. I68, I903.

(30) Carpenter, C. M., Boak, Ruth A., Mucci, L. A., and Warren,

S. L. : "Studies on the Physiologic Effects of Fever Temperatures,"

J. Lab. and Clin. Med., 18, pp. 98I-99I, July, I933.

(3I) Carpenter, C. M., Boak, R. A., and Warren, S. L.: "The

Basic Principles for the Cure of Gonococcal Infections by a Single Fever Treatment," Proc. Fifth Fever Conf., Dayton, Ohio, pp. 5-6., May, I935. (32) Desjardins, A. U., Stuhler, L. G., and Popp, W. C. : “Fever Therapy for Gonococcic Infections," J.A.M.A., 104, pp. 873-878, March I6th, I935.

(33) Hench, P. S., Slocumb, C. H., and Popp, W. C. : "Fever Therapy: Results for Gonorrhœal Arthritis, Chronic Infectious (Atrophic) Arthritis, and other Forms of 'Rheumatism,' " J.A.M.A., 104, pp. I779-I790, May I8th, I935.

(34) Desjardins, A. U., Stuhler, L. G., and Popp, W. C. : “ Fever Therapy for Gonococcic Infections, II.," J.A.M.A., 106, pp. 69o-699, February, 29th, I936.

(35) Carpenter, C. M., and Warren, S. L. : " Artificially Induced Fever in the Treatment of Disease," New York State J. Med., 23, pp. 997-IO0I, September Ist, I932.

(36) Bishop, F. W., Horton, C. B., and Warren, S. L. : " A Clinical Study of Artificial Hyperthermia induced by High Frequent Currents," Am.J.M.Sc., 184, pp. 5I5-533, October, I932.

(37) Tenney, C. F. : "Artificial Fever produced by the Short-wave Radio and Its Therapeutic Application," Ann. Int. Med., 6, pp. 457468, October, I932.

(38) Warren, S. L., and Wilson, K. M.: "The Treatment of Gonococcal Infections by Artificial (General) Hyperthemia," Am. J. Obst. and Gynec., 24, pp. 592-598, October, I932.

(39) BERrIS, J. M.: "The Treatment of Arthritis by Artificial Fever: Preliminary Report of Twenty Cases," J. Michigan M. Soc., 32, pp. 355-358, June, I933.

(40) Simpson, Walter M., Kislig, F. K., and Sittler, E. C. : "Ultra-high Frequency Pyretotherapy of Neurosyphilis: A Preliminary Report," Ann. Int. Med., \%, pp. 64-75, July, I933.

(4I) Atsatt, R. F., and Patterson, L. E. : "The Use of Electropyrexia in Gonorrhœal Arthritis," Physiotherapy Rev., 13, pp. I44-I46, July-August, I933.

(42) Kovacs, R., and Kovacs, J. : "Physical and Constitutional Measures in Chronic Arthritis," New York State J. Med., 33, pp. II48II54, October Ist, I933.

(43) Simpson, Walter M.: "Artificial Fever Therapy," Proc. Staff Meet. Mayo Clinic, 9, pp. 567-57I, September I9th, I934. 


\section{BRITISH JOURNAL OF VENEREAL DISEASES}

(44) Hench, P. S.: “The Present Status of Fever Therapy in the Treatment of Gonorrhœal Arthritis, Gonococcic Infectious (Atrophic) Arthritis, and other Forms of 'Rheumatism,' " J. Lab. and Clin. Med., 21, pp. 524-53I, February, I936.

(45) Schnabel, Truman, G., and Fetter, Ferdinand: "Fever Therapy in Gonorrhœal Arthritis and Chorea," Ann. Int. Med., 9, pp. 398-405, October, I935.

(46) Anderson, T. B. H., Arnold, R. C., and Trautman, J. A. : "The Treatment of Gonococcal Infections in the Male with Pyretotherapy," Proc. Fifth Fever Conf., Dayton, Ohio, pp. 33-34, May, I935.

(47) Faget, G. H. : “Discussion,” Proc. Fifth Fever Conf., Dayton, Ohio, pp. 34-35, May, I935.

(48) Bierman, W., and Horowitz, E. A. : "Treatment of Gonorrhœa in the Female by Means of Systemic and Additional Pelvic Heating," J.A.M.A., 104, pp. I797-I801, May I8th, I935.

(49) Stuhler, L. G.: "Fever Therapy of Gonococcal Infections," Proc. Staff Meet. Mayo Clin., 10, pp. 207-208, March 27th, I935. 